\title{
The Mooring system design based on Genetic Algorithm
}

\author{
Yating $\mathrm{Liu}^{1, \mathrm{a}}$ \\ ${ }^{1}$ North China Electric Power University, Baoding 071000, China \\ ayating1995@foxmail.com
}

\begin{abstract}
Mooring system design problem is to determine the anchor chain type, length and weight of the ball to make the buoy of the draft depth and swimming area and the angle of inclination of steel drum as small as possible. In this paper, we proposed the mooring system optimization design by mechanical analysis. Because the wind speed on sea surface and sea water velocity direction may not be located in the same plane, so we established three-dimensional coordinate system. And then we deduced the force relation between the objects. Then we regarded the depth, radius and angle of inclination of the winding drums as the optimization goal. By Genetic algorithm we obtain the chain number and length, the quality of heavy ball to make the mooring system under different external conditions (water depth, water velocity and wind speed) safe and stable.
\end{abstract}

Keywords: Mooring system, Genetic algorithm.

\section{Introduction}

A mooring system is shown as Fig.1. Due to tidal, layout of the waters measured depth of $16 \mathrm{~m} \sim 20 \mathrm{~m}$. The maximum velocity of the seawater is $1.5 \mathrm{~m} / \mathrm{s}$ and the maximum wind speed is $36 \mathrm{~m} / \mathrm{s}$. We obtain the mooring system design considering wind, water flow and water depth. Analyze the inclination angle, anchor shape, bucket depth and buoying area of steel drum and steel pipe under different conditions.

\section{The establishment of three-dimensional coordinate system}

In order to discuss and express the entire state clearly, a three-dimensional coordinate system will be used. As Fig. 1 shown, we establish the coordinate system, in which $\mathrm{Z}$ direction is buoyancy direction and $\mathrm{x} y$ plane is the seabed plane.

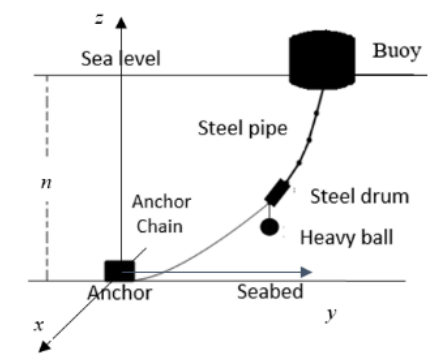

Fig.1 Three-dimensional coordinate system

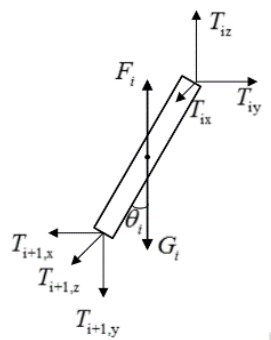

Fig.2 Analysis of steel pipe under force

There may be an angle between the sea surface wind speed and sea water velocity. At the same time, in order to facilitate the data calculation and processing, the sea surface wind and sea water velocity were decomposed into the $\mathrm{X}$ axis, $\mathrm{Y}$ axis. Select a steel pipe for example:

$$
\left\{\begin{array}{l}
F_{x h}=0 \\
F_{y h}=0 \\
F_{z h}=0
\end{array}\right.
$$

Where $\mathrm{F}_{x h}, \mathrm{~F}_{y h}, \mathrm{~F}_{z h}$ represent the forces in the X-axis, Y-axis and Z-axis directions. 
Analogy two-dimensional case, the force is broken down along the rod direction, along the vertical direction of the bar. The specific analysis and the equilibrium equation are similar to the two-dimensional case.

\section{Genetic algorithm specific process}

According to the conditions set, the depth of the layout of the sea, sea and wind speed are in a certain range. While the weight of the ball is also unknown. Therefore, we construct the genetic algorithm model to optimize moving radius and inclination angle of the drum.

\subsection{Genetic algorithm detailed design}

According to the conditions set, the depth of the layout of the sea, the sea speed, the wind speed is a certain range, while the weight of the heavy ball is unknown, so you can draft depth, swimming radius and steel drum tilt angle for the optimization target, Genetic algorithm model. The specific process is as follows:

1) Constructing fitness function

In fact, the tilt angle of steel drums and the draft y0 and swimming radius $r$ of should as far as possible to meet the conditions of the small, but the variable is not in an order of magnitude, so without any treatment directly into the fitness function will cause great error. So the idea of structure modeled on the normalized fitness function are as follows:

$$
\min W=\frac{\theta_{5}}{5}+\frac{y_{0}}{2}+\frac{r^{2}}{400}
$$

2) Linear constraint condition

According to the analysis of the three-dimensional force in (2), the total force of each steel pipe, the heavy ball and the anchor chain in the $\mathrm{X}$ direction, the $\mathrm{Y}$ direction and the $\mathrm{Z}$ direction equal 0 . Namely the system is in a state of equilibrium:

$$
\left\{\begin{array}{l}
F_{x 1}+F_{x 2}+\cdots+F_{x a}=0 \\
F_{y 1}+F_{y 2}+\cdots+F_{y a}=0 \\
F_{z 1}+F_{z 2}+\cdots+F_{z a}=0
\end{array}\right.
$$

Where a is the number of objects subjected to force.

At the same time, the position of the anchor chain is at the same plane as the seabed: $\mathrm{y}-\mathrm{h}=0$.

The radius of $\mathrm{R}$ needs to be satisfied: $\mathrm{r}=\sqrt{\mathrm{x}_{0}^{2}+\mathrm{y}_{0}^{2}}$

Which represents the coordinates of buoys.

The number of anchor cables $n$ is determined by the length of the anchor chain $L$ and the length of each anchor chain $I: \mathrm{n}=\frac{\mathrm{l}}{\mathrm{I}}$.

3) Absolute and non-negative constraints

According to the tilt angle and the angle of the anchor chain and seabed limit:

$$
\left\{\begin{array}{l}
0 \leq \theta_{5} \leq 5^{\circ} \\
0 \leq 90-\theta_{251} \leq 16^{\circ}
\end{array}\right.
$$

The depth, sea speed and wind speed also need to be met:

$$
\left\{\begin{array}{l}
16 \leq h \leq 20 \\
0 \leq v_{h} \leq 1.5 \\
0 \leq v_{f} \leq 36
\end{array}\right.
$$

At the same time, the buoy cannot all fall into the sea bottom, that is, the draft depth of Y0 should satisfy:

$$
0<y_{0}<2
$$

4) Genetic algorithm calculation 
Call the MATLAB GA function of genetic algorithm. Use the fitness function and the constraint conditions to get the best draught, radius $\mathrm{R}$ and the inclination angle of the drum.

Tab.1 Different situation

\section{Specific situation}

\begin{tabular}{|r|l|}
\hline $\mathbf{1}$ & Depth=16m, wind and water is in same direction, their speed are the maximum value. \\
\hline $\mathbf{2}$ & Depth $=16 \mathrm{~m}$, wind and water is in opposite direction, their speed are the maximum value. \\
\hline $\mathbf{3}$ & Depth=18m, wind and water is in same direction, their speed are the maximum value. \\
\hline $\mathbf{4}$ & Depth=18m, wind and water is in opposite direction, their speed are the maximum value. \\
$\mathbf{6}$ & Depth=20m, wind and water is in same direction, their speed are the maximum value. \\
\hline & Depth=20m, wind and water is in opposite direction, their speed are the maximum value. \\
\hline
\end{tabular}

The results of optimal anchor type and heavy ball quality are obtained by previous. In order to simplify the calculation, we only consider water and wind flow direction are equal and opposite. When the water depth is 16/18/20m respectively. The results are as follows:

Table 2 The result of Different situation

\begin{tabular}{|c|c|c|c|c|c|c|}
\hline & 1 & 2 & 3 & 4 & 5 & 6 \\
\hline Swimming radius $(\mathrm{m})$ & 19.1 & 17.5 & 18.2 & 15.30 & 17.19 & 14.10 \\
\hline Swimmıng radius $(\mathrm{m})$ & 7 & 3 & 9 & 1 & 3 & 9 \\
\hline Draft depth of buoy（m) & $\begin{array}{c}1.32 \\
9\end{array}$ & $\begin{array}{c}1.36 \\
9\end{array}$ & $\begin{array}{c}1.31 \\
6\end{array}$ & 1.359 & 1.301 & 1.354 \\
\hline Inclined angle of steel pipe $1\left(^{\circ}\right)$ & $\begin{array}{c}3.96 \\
9\end{array}$ & $\begin{array}{c}0.06 \\
9\end{array}$ & $\begin{array}{c}4.09 \\
8\end{array}$ & 0.070 & 4.252 & $\begin{array}{c}0.071 \\
2\end{array}$ \\
\hline Inclined angle of steel pipe $2\left(^{\circ}\right)$ & $\begin{array}{c}4.05 \\
5\end{array}$ & $\begin{array}{c}0.14 \\
1\end{array}$ & $\begin{array}{c}4.18 \\
5\end{array}$ & 0.144 & 4.340 & 0.145 \\
\hline Inclined angle of steel pipe $3\left(^{\circ}\right)$ & $\begin{array}{c}4.14 \\
0\end{array}$ & $\begin{array}{c}0.21 \\
5\end{array}$ & $\begin{array}{c}4.27 \\
2\end{array}$ & 0.218 & 4.429 & 0.219 \\
\hline Inclined angle of steel pipe $4\left(^{\circ}\right)$ & $\begin{array}{c}4.22 \\
6\end{array}$ & $\begin{array}{c}0.28 \\
8\end{array}$ & $\begin{array}{c}4.36 \\
0\end{array}$ & 0.292 & 4.518 & 0.294 \\
\hline Inclined angle of steel pipe $5\left(^{\circ}\right)$ & $\begin{array}{c}4.31 \\
3\end{array}$ & $\begin{array}{c}0.36 \\
2\end{array}$ & $\begin{array}{c}4.44 \\
7\end{array}$ & 0.367 & 4.607 & 0.369 \\
\hline
\end{tabular}

According to the data of the anchor cable, the image can be made in the three-dimensional coordinate system, and only the image in the first case can be drawn:

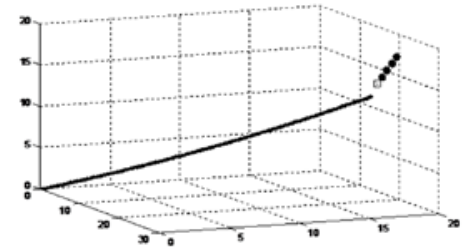

Fig.3 The shape of anchor chain

By the analysis of theoretical mechanics and genetic algorithm, the parameters of the optimal mooring system can be obtained, so that the design of the mooring system can achieve the desired effect.

\section{Conclusions}

This model can directly influence the key part of the system analysis.so that we can get safe, stable operation of the system condition. But we can optimize and improved for each step and use multi window mutation to get a better system conditions to fit the actual situation.

\section{References}


[1]Gao Yue. Modified Algorithm of Sinusoid Signal Frequency Estimation Based on Quinn and Aboutanios Iterative Algorithms[A]. IEEE Beijing Section、 IET Beijing Local Network、Beijing Jiaotong University.2016 IEEE 13th International Conference on Signal Processing Proceedings ( ICSP2016 ) [C].IEEE Beijing Section、 IET Beijing Local Network 、Beijing Jiaotong University:,2016:4.

[2]Cao Yalu,Peng Li,Li Jinzhou,Yang Le,Guo Fucheng. A new iterative algorithm for geolocating a known altitude target using TDOA and FDOA measurements in the presence of satellite location uncertainty[J]. Chinese Journal of Aeronautics,2015,(05):1510-1518.

[3]YANG Xue,WANG Hongbo,SUN Li,YU Hongnian. Operation and Force Analysis of the Guide Wire in a Minimally Invasive Vascular Interventional Surgery Robot System[J]. Chinese Journal of Mechanical Engineering,2015,(02):249-257.

[4]. Design of artificial neural networks using a genetic algorithm to predict saturates of vacuum gas oil[J]. Petroleum Science,2010,(01):118-122.

[5]. An iterative algorithm for solving a class of matrix equations[J]. Journal of Control Theory and Applications,2009,(01):68-72.

[6]. Adaptive interactive genetic algorithms with individual interval fitness[J]. Progress in Natural Science,2008,(03):359-365. 